Vlaar, A.P.J., Hofstra, J.J., Determann, R.M., Veelo, D.P., Paulus, F., Kulik, W., Korevaar, J., Mol, B.A. de, Koopman, M.M.W., Porcelijn, L., Binnekade, J.M., Vroom, M.B., Schultz, M.J., Juffermans, N.P. The incidenge risk factors, and outcome of transfusion-related acute lung injury in a cohort of cardiac surgery patients.a prospective nested case-control study. Blood: 2011, 117(16), 4218-4225

\begin{tabular}{|l|l|}
\hline Postprint Version & 1.0 \\
\hline Journal website & http://bloodjournal.hematologylibrary.org/content/117/16/4218.long \\
\hline Pubmed link & http://www.ncbi.nlm.nih.gov/pubmed/21325598 \\
\hline DOI & $10.1182 /$ blood-2010-10-313973 \\
\hline
\end{tabular}

This is a NIVEL certified Post Print, more info at http://www.nivel.eu

\title{
The incidence, risk factors, and outcome of transfusion- related acute lung injury in a cohort of cardiac surgery patients: a prospective nested case-control study
}

\author{
AleXander P. J. VlaAr ${ }^{13}$, Jorrit J. Hofstra ${ }^{1},{ }^{4}$, Rogier M. DetermanN ${ }^{1}, 2$, Denise P. Veelo ${ }^{1},{ }^{4}$, \\ FrederiQue PAULus ${ }^{1}$, WIM KULIK ${ }^{5}$, JOHANNA KOREVAAR ${ }^{6}$, BAS A. DE MOL ${ }^{7}$, MARIANNE M. W. \\ KOOPMAN $^{8}$, LEENDERT PORCELIJN ${ }^{8}$, JAN M. BINNEKADE ${ }^{1}$, MARGREETH B. VROOM ${ }^{1}$, MARCUS J. \\ SCHULTZ ${ }^{1}$, , AND NICOLE P. JUfFERMANS ${ }^{1,}$ \\ ${ }^{1}$ Department of Intensive Care Medicine, \\ ${ }^{2}$ Department of Internal Medicine, \\ ${ }^{3}$ Laboratory of Experimental Intensive Care and Anesthesiology, \\ ${ }^{4}$ Department of Anesthesiology, \\ ${ }^{5}$ Laboratory of Genetic Metabolic Diseases, \\ ${ }^{6}$ Department of Epidemiology and Bio-statistics, and \\ ${ }^{7}$ Department of Cardiac Thoracic Surgery, Academic Medical Center, Amsterdam, The Netherlands; and \\ ${ }^{8}$ Sanquin Blood Supply Foundation, Amsterdam, The Netherlands
}

\begin{abstract}
Transfusion-related acute lung injury (TRALI) is the leading cause of transfusion-related morbidity and mortality. Both antibodies and bioactive lipids that have accumulated during storage of blood have been implicated in TRALI pathogenesis. In a single-center, nested, casecontrol study, patients were prospectively observed for onset of TRALI according to the consensus definition. Of 668 patients, 16 patients $(2.4 \%)$ developed TRALI. Patient-related risk factors for onset of TRALI were age and time on the cardiopulmonary bypass. Transfusion-related risk factors were total amount of blood products (odds ratio $[\mathrm{OR}]=1.2$; $95 \%$ confidence interval [CI], 1.03-1.44), number of red blood cells stored more than 14 days $(\mathrm{OR}=1.6 ; 95 \% \mathrm{CI}, 1.04-2.37)$, total amount of plasma $(\mathrm{OR}=1.2 ; 95 \% \mathrm{CI}, 1.03-1.44)$, presence of antibodies in donor plasma $(\mathrm{OR}=8.8 ; 95 \% \mathrm{CI}, 1.8-44)$, and total amount of transfused bioactive lipids $(\mathrm{OR}=1.0 ; 95 \% \mathrm{CI}, 1.00-1.07)$. When adjusted for patient risk factors, only the presence of antibodies in the associated blood products remained a risk factor for TRALI (OR $=14.2 ; 95 \%$ CI, 1.5-132). In-hospital mortality of TRALI was $13 \%$ compared with $0 \%$ and $3 \%$ in transfused and nontransfused patients, respectively $(\mathrm{P}<.05)$. In conclusion, the incidence of TRALI is high in cardiac surgery patients and associated with adverse outcome. Our results suggest that cardiac surgery patients may benefit from exclusion of blood products containing HLA/HNA antibodies.
\end{abstract}

\section{INTRODUCTION}

Transfusion-related acute lung injury (TRALI) is the leading cause of transfusion-related morbidity and mortality. ${ }^{1-4}$ TRALI is defined as the acute onset of hypoxia and bilateral pulmonary infiltrates, in temporal relation to a blood transfusion. ${ }^{1,5}$ Although the absence of specific disease markers and diagnostic tests has resulted in a large variation in estimations of incidence, ${ }^{1,6-14}$ TRALI is generally considered to be a rare 
Vlaar, A.P.J., Hofstra, J.J., Determann, R.M., Veelo, D.P., Paulus, F., Kulik, W., Korevaar, J., Mol, B.A. de, Koopman, M.M.W., Porcelijn, L., Binnekade, J.M., Vroom, M.B., Schultz, M.J., Juffermans, N.P. The incidenge risk factors, and outcome of transfusion-related acute lung injury in a cohort of cardiac surgery patients. prospective nested case-control study. Blood: 2011, 117(16), 4218-4225

event. However, TRALI is underdiagnosed and under-reported. ${ }^{15,16}$ Cases remain unnoticed or are misdiagnosed as fluid overload or acute lung injury (ALI) of other etiology. ${ }^{15,17,18}$ As yet, controlled trials using standardized definitions of TRALI are limited. ${ }^{6}$

TRALI is thought to be a 2-event entity. The "first event" is the presence of an inflammatory condition in the host, causing endothelial activation leading to neutrophil sequestration and priming in the lung. ${ }^{19}$ The "second event" is transfusion of a blood product containing either antibodies or factors that accumulate during storage, providing additional signals for neutrophil activation resulting in the clinical syndrome of pulmonary edema. Two distinct mechanisms have been suggested for the "second event": the traditional theory proposes an antibody-mediated reaction between recipient neutrophils and antineutrophil antibodies from donors who were sensitized during pregnancy (multiparous women) or by previous transfusion. ${ }^{7,15,20}$ An alternative mechanism involves accumulation of bioactive lipids (lysophosphatidylcholines [lysoPCs]) during storage of cell containing blood products. ${ }^{21-23}$

Cardiac surgery patients may be at risk for TRALI. During the intrathoracic surgical procedure, the lungs are deflated and nonventilated for several hours, which may cause injury to the lung vasculature (the "first event"). In addition, the use of cardiopulmonary bypass can cause neutrophil priming. ${ }^{24,25}$ In retrospective studies, cardiac surgery was a risk factor for the onset of TRALI. ${ }^{9,10}$ Besides possible priming factors, these patients often receive transfusion of blood products. ${ }^{26}$

Several transfusion policies may have potential in decreasing TRALI incidence. Routine exclusion of women donors in production of fresh frozen plasma (FFP) decreases TRALI incidence in observational studies. ${ }^{27-29}$ Transfusion of fresh red blood cells (RBCs) only was associated with fewer pulmonary complications in cardiac surgery patients, ${ }^{30}$ but results have not been confirmed by others. ${ }^{31-33}$ Without doubt, both the deferral of female donors as well as the use of fresh blood only have serious consequences for blood availability. Insight in incidence and risk factors for TRALI are mandatory to improve product management strategies as well as donor-exclusion policies aimed at decreasing the risk of acquiring TRALI without impeding a continuous reliable blood supply.

We performed a prospective case-control study in a cohort of cardiac surgery patient to determine incidence, risk factors, and outcome of TRALI.

\section{METHODS}

The medical ethics committee of the Academic Medical Center, Amsterdam, approved the study protocol, and written informed consent was obtained from the patient in accordance with the Declaration of Helsinki before entry in the study. Consecutive patients of 18 years and older were asked informed consent before undergoing cardiac surgery. Exclusion criteria were pulmonary thromboendarterectomy or emergency surgery. Investigators consecutively screened 1000 cardiac surgery patients from November 2006 until February 2009. Included patients were observed for the onset of TRALI during surgery and afterward up to 30 hours on the intensive care unit (ICU).

\section{Setting and cardiothoracic surgery/anesthesia procedures}

The study was performed in a university hospital in The Netherlands. Patients were anesthetized according to local institutional protocol, with lorazepam as premedication followed by etomidate, sufentanil, and rocuronium for induction of anesthesia and facilitation of intubation. During the surgical procedure, sufentanil was used as analgesic, and sevoflurane plus propofol were used to maintain anesthesia. Muscle relaxants were not given during the surgical procedure. Small doses of morphine and midazolam could be given at the end of the procedure. Steroids were given at the discretion of the cardioanesthesiologist. As part of standard care, a pulmonary artery catheter was inserted for perioperative monitoring.

In all patients, cardiopulmonary bypass was performed under mild to moderate hypothermia $\left(28^{\circ} \mathrm{C}\right.$ to $34^{\circ} \mathrm{C}$ ), using a membrane oxygenator and a nonpulsatile blood flow. During the procedure, lungs were deflated. After the procedure, all patients were transferred to the ICU with mechanical ventilation.

\section{ICU management}

The postoperative ICU protocol involved fluid infusion with normal saline and starch solutions, blood transfusion to maintain hemoglobin concentration $(\geq 5.0 \mathrm{mM})$, dopamine and norepinephrine in continuous infusion to achieve mean arterial blood pressure more than or equal to $65 \mathrm{mmHg}$, and dobutamine and/or milrinone to achieve a cardiac index more than or equal to $2.5 \mathrm{~L} / \mathrm{min} / \mathrm{m}^{2}$ or a mixed venous oxygenation 
Vlaar, A.P.J., Hofstra, J.J., Determann, R.M., Veelo, D.P., Paulus, F., Kulik, W., Korevaar, J., Mol, B.A. de, Koopman, M.M.W., Porcelijn, L., Binnekade, J.M., Vroom, M.B., Schultz, M.J., Juffermans, N.P. The incidenqe risk factors, and outcome of transfusion-related acute lung injury in a cohort of cardiac surgery patients. a prospective nested case-control study. Blood: 2011, 117(16), 4218-4225

more than $60 \%$. Propofol was continuously infused until core temperature reached $36.0^{\circ} \mathrm{C}$, after which propofol infusion was stopped. Analgesics include acetaminophen and morphine.

\section{Design}

TRALI cases were 1:2 randomly (http://www.randomizer.org/) matched with control patients. Cases were not matched on potential risk factors, such as age, type of surgery, or sex as in this way potential risk factors for the onset of TRALI could be eliminated by design. Controls were transfused patients not developing ALI and patients not transfused not developing ALI. Since June 1, 2007, exclusion of female donors for FFP became effective in The Netherlands. For this reason, matching was done separate for patients included before or after June $1,2007 .^{28}$

Possible TRALI was defined using the consensus definition of TRALI (new onset hypoxemia or deterioration demonstrated by arterial oxygen tension/fraction of inspired oxygen $<300 \mathrm{mmHg}$, within 6 hours after transfusion, with bilateral pulmonary changes, in the absence of elevated left atrial pressure defined as a pulmonary arterial occlusion pressure less than or equal to $18 \mathrm{mmHg}$ ). ${ }^{1,3,5}$ Chest radiographs were routinely taken before surgery and on arrival at the ICU and scored for the presence of new onset bilateral interstitial abnormalities by 2 independent physicians blinded to the predictor variables. When interpretation differed, chest radiograph and the description by the radiologist were reviewed to receive consensus.

\section{Patient data collection}

Potential risk factors for onset of ALI were scored, including alcohol abuse, smoking, myocardial infarction, hypertension, diabetes, vascular diseases, hematologic and solid malignancy, cerebrovascular accidents, autoimmune disease, chronic obstructive pulmonary disease, and diminished left ventricular function. ${ }^{5}$ Data on preoperative blood values and perioperative data were extracted from the electronic patient data system as well as ventilation time, hospital stay, and mortality. The European System for Cardiac Operative Risk Evaluation (EUROscore) and American Association of Anesthesiology (ASA) score were preoperatively scored by the cardiac surgeon and anesthesiologist, respectively. Both scores calculate a score that indicates the mortality risk of the surgery and the physical status classification of the patient before surgery, respectively.

\section{Transfusion data collection}

Transfused RBCs were leuko-reduced (buffy coat removed and the erythrocyte suspension was filtered to remove the leukocytes to $<1 \times 10^{6}$ ). The start and stop time of the transfusion was recorded by the bedside nurse and entered in the electronic patient data system. FFP and platelet concentrates (PLT) products were defined as high-volume plasma products. The volume of plasma transfused was calculated as the sum of $325 \mathrm{~mL}$ per unit of FFP and $250 \mathrm{~mL}$ per PLT. Data on donor sex and storage time of the blood products were obtained from the National Blood Bank. The PLT concentrates were pooled products using 5 donor buffy coats, with one of the 5 donors to provide the plasma fraction. Only the sex of the donor providing the plasma fraction was taken into account for donor sex analysis. All products transfused during cardiac surgery and postoperatively up to 24 hours after ICU admission were sampled and stored until the patient was assigned to a study group. Samples of the blood bags were centrifuged $\left(1500 \mathrm{~g}\right.$ for 10 minutes at $4^{\circ} \mathrm{C}$ for $\mathrm{RBCs}$ and at $22^{\circ} \mathrm{C}$ for PLTs), and the supernatant was stored at $-80^{\circ} \mathrm{C}$ until further analysis.

\section{Lipid extraction and lysoPC and PC measurement}

Lipid extraction of supernatant from stored RBCs and PLTs supernatant was performed using Bligh and Dyer method. In short, $3 \mathrm{~mL}$ of $\mathrm{CHCl}_{3}: \mathrm{MeOH}(1: 2)$ was added to $100 \mu \mathrm{L}$ of sample and $100 \mu \mathrm{L}$ of internal standard solution (LysoPC 14:0, $2.5 \mathrm{nmol}$; and PC 28:0, $10 \mathrm{nmol}$ ). A total of $700 \mu \mathrm{L} \mathrm{HAc} 0.5 \%, 1 \mathrm{~mL}$ $\mathrm{CHCl}_{3}$, and $800 \mu \mathrm{L}$ of $\mathrm{HAc} 0.5 \%$ were added. After each step, samples were vortexed for 30 seconds. The final mixture was centrifuged for 10 minutes at $1892 \mathrm{~g}$ at room temperature. After centrifugation, the lower layer of $\mathrm{CHCl}_{3}$ was separated. This step was repeated 2 times by adding $1 \mathrm{~mL} \mathrm{CHCl}$. The separated $\mathrm{CHCl}_{3}$ layers were combined and dried $\left(\mathrm{N}_{2}, 30^{\circ} \mathrm{C}\right)$. Samples were dissolved in $150 \mu \mathrm{L} \mathrm{CHCl} 3 / \mathrm{MeOH} / \mathrm{H}_{2} \mathrm{O} / \mathrm{NH}_{3}$ $25 \%(50 / 45 / 5 / 0.01 \mathrm{vol} / \mathrm{vol} / \mathrm{vol} / \mathrm{vol})$ for further analysis.

\section{HPLC tandem mass spectrometry}

The relative concentrations of lysoPCs species in supernatant of RBCs and PLTs were determined using high performance liquid chromatography tandem mass spectrometry (HPLC-MS/MS). A total of $10 \mu \mathrm{L}$ of 
Vlaar, A.P.J., Hofstra, J.J., Determann, R.M., Veelo, D.P., Paulus, F., Kulik, W., Korevaar, J., Mol, B.A. de, Koopman, M.M.W., Porcelijn, L., Binnekade, J.M., Vroom, M.B., Schultz, M.J., Juffermans, N.P. The incidenqe risk factors, and outcome of transfusion-related acute lung injury in a cohort of cardiac surgery patients: 2 prospective nested case-control study. Blood: 2011, 117(16), 4218-4225

the lipid extraction was injected on the HPLC-MS/MS system. Chromatographic separation was achieved on a modular HPLC system (Surveyor; Thermo Finnigan) consisting of a cooled autosampler $\left(\mathrm{T}=12^{\circ} \mathrm{C}\right)$, a low-flow quaternary MS pump and analytical HPLC column: LichroSpher Si60, $2 \times 250-\mathrm{mm}$ column, 5- $\mu \mathrm{m}$ particle diameter (Merck). Samples were eluted with a flow rate of $300 \mu \mathrm{L} /$ minute and a programmed linear gradient between solution B (chloroform-methanol, 97:3, vol/vol) and solution A (methanol-water, 85:15, $\mathrm{vol} / \mathrm{vol}$ ); $\mathrm{A}$ and $\mathrm{B}$ contained $1 \mathrm{~mL}$ and $0.1 \mathrm{~mL}$ of $25 \%$ (vol/vol) aqueous ammonia per liter of eluent, respectively. The gradient was: $\mathrm{T}=0$ to 10 minutes: $20 \% \mathrm{~A}$ to $100 \% \mathrm{~A} ; \mathrm{T}=10$ to 12 minutes, $100 \% \mathrm{~A} ; \mathrm{T}=$ 12 to 12.1 minutes: $100 \%$ A to $0 \% \mathrm{~A}$; and $\mathrm{T}=12.1$ to 17 minutes, equilibration with $0 \% \mathrm{~A}$. Total run-time, including the equilibration, was 17 minutes. A splitter between the HPLC and MS was used for the introduction of the eluent in the MS by $75 \mu \mathrm{L} /$ minutes.

MS/MS analyses were performed on a TSQ Quantum AM (Thermo Finnigan) operated in the positive ion electrospray ionization mode. The Skimmer Offset was set at $10 \mathrm{~V}$; spray voltage was $3600 \mathrm{~V}$ and the capillary temperature was $300^{\circ} \mathrm{C}$. In the optimized MS/MS experiments, argon was used as collision gas at a pressure of $0.07 \mathrm{~Pa}$ and a collision energy of $40 \mathrm{~V}$. The parent ion scan of mass to charge ratio $(\mathrm{m} / \mathrm{z})$ of 184.1 ( $\mathrm{m} / \mathrm{z} 400-1000,1$ second) was used for the quantization of the following precursor ions: $\mathrm{m} / \mathrm{z} 468.3$ (LysoPC 14:0, internal standard), m/z 496.3 (LysoPC 16:0), m/z 524.3 (LysoPC 18:0/ PAF 16:0), m/z 522.4 (LysoPC 18:1), m/z 482.4 (LysoPAF 16:0), m/z 510.4 (LysoPAF 18:0), and m/z 508.4 (LysoPAF 18:1). LysoPC levels are presented as total amount of lysoPC infused (volume for lysoPCs is calculated as RBCs $120 \mathrm{~mL}$ and PLTs $250 \mathrm{~mL}$ ) and as median concentration per product transfused.

\section{Donor antibody analysis}

Leukocyte reactive antibodies were examined in samples freshly drawn from donors of associated blood products. Samples were screened for HLA antibodies using a standard complement-dependent cytotoxicity assay with an HLA-typed donor panel (to detect complement-fixing antibodies to HLA class I and II) ${ }^{34}$ and a Luminex screening assay for HLA class I and II (Tepnel Lifecode Luminex Screen Deluxe). HLA class I and II antibodies were identified using a luminex single antigen bead technology (Tepnel Lifecode Luminex). Lymphocyte-reactive antibodies were examined by the Lymphocyte ImmunoFluorescence Test. ${ }^{35}$ Leukocyte agglutinating anti-bodies (HNA-3a) were examined by the Leukocyte Agglutination Technique ${ }^{36}$ Granulocyte-reactive antibodies (HNA-1a, -1b, -1c, and -2a) were examined by the Granulocyte ImmunoFluorescence Test. ${ }^{37}$ HNA-1a, 1b, 2a, and 3a were typed in the Granulocyte ImmunoFluorescence Test. Finally, the detected antibodies were confirmed in the Monoclonal Antibody Immobilization of Granulocyte Antigens assay, as previously described. ${ }^{38}$

\section{Statistics}

We anticipated that approximately $80 \%$ of case subjects and $10 \%$ of control subjects will have received at least 1 unit of donor blood that tested positive for antileukocyte antibodies. ${ }^{9,39,40}$ It was determined that a 1:2 matched case-control study with 15 case subjects and 30 control subjects would provide more than $80 \%$ power to detect a significant difference in the number of positive antibody tests between groups, using a 2sided, $\alpha=.05$ level test. Data were checked for distribution. Normal distributed data were analyzed using analysis of variance and Dunnett posttest. Nonparametric data were analyzed with Kruskal-Wallis or MannWhitney $U$ test. Categorical data were analyzed with the $\chi^{2}$ test. To evaluate independent potential predictors of TRALI, a univariate analysis followed by a multivariate logistic regression analysis was performed. We used both statistical and relevant clinical criteria in the selection process. Statistical analysis was performed with SPSS Version 15.0.

\section{RESULTS}

\section{Incidence}

A total of 1000 cardiac surgery patients were screened consecutively for inclusion. Of these, 99 patients did not fulfill the inclusion criteria (Figure 1). Another 233 patients did not give informed consent, leaving 668 patients for inclusion in the study. Of these, 16 patients (2.4\%) developed possible TRALI. In total, 2631 blood products were transfused, concerning 747 FFP units, 1610 RBC units, and 274 PLTs. The incidence of possible TRALI per product transfused was $0.61 \%$. Only one patient was reported to the transfusion laboratory by the attending physician as possible TRALI. 
Vlaar, A.P.J., Hofstra, J.J., Determann, R.M., Veelo, D.P., Paulus, F., Kulik, W., Korevaar, J., Mol, B.A. de, Koopman, M.M.W., Porcelijn, L., Binnekade, J.M., Vroom, M.B., Schultz, M.J., Juffermans, N.P. The incidenqe risk factors, and outcome of transfusion-related acute lung injury in a cohort of cardiac surgery patients: 2 prospective nested case-control study. Blood: 2011, 117(16), 4218-4225

\section{[FIGURE 1]}

\section{Patient-related risk factors}

Patients developing TRALI were older compared with transfused controls and nontransfused controls $(\mathrm{P}<$ .05 and $\mathrm{P}<.01$, respectively; Table 1). In addition, patients developing TRALI had a higher EUROscore and ASA score compared with nontransfused controls $(\mathrm{P}<.05$ and $\mathrm{P}<.01$, respectively). Groups did not differ in other risk factors for ALI, preoperative lung function, cardiac function, and type of surgery (Table 1). Patients developing TRALI had a longer clamp, pump, and surgery time compared with transfused controls and nontransfused controls $(\mathrm{P}<.01, \mathrm{P}<.001$, and $\mathrm{P}<.001$, respectively; Table 1$)$. Transfused patients not meeting the TRALI definition also had a longer clamp, pump, and surgery time compared with nontransfused controls $(\mathrm{P}<.01, \mathrm{P}<.05$, and $\mathrm{P}<.05$, respectively; Table 1$)$. No differences were observed between groups concerning the amount of corticosteroids and opiates used perioperatively.

\section{[TABLE 1]}

Multivariate logistic regression analysis showed that age and time on cardiopulmonary bypass are risk factors for developing TRALI compared with transfused controls $(\mathrm{P}=.03$ and 0.02 , respectively; Table 4).

\section{Transfusion-related risk factors}

Patients developing TRALI received more RBC, FFP, and PLT products compared with transfused controls $(\mathrm{P}<.05$ for all; Table 2$)$. Median storage time of RBCs did not differ between groups. Although not reaching statistical significance, the number of transfused RBC units stored more than 14 days tended to be higher in patients developing TRALI compared with transfused controls. Storage time of PLT products did not differ between patient groups.

\section{[TABLE 2]}

LysoPC concentration was determined in $77 \%$ of all associated cell containing blood products (ie, transfused within the 6-hour time frame before onset of TRALI). The amount of lysoPCs in all transfusion products taken together was higher in the patients developing TRALI compared with transfused controls ( $\mathrm{P}$ $<.01$ for all). However, the amount of lysoPC per product transfused did not differ between TRALI and transfused controls.

Patients developing TRALI received higher amounts of high-volume plasma products (FFP and PLTs) compared with transfused controls $(\mathrm{P}=.01)$. In $67 \%$ of all associated blood products, donor samples were retrieved for analysis of HLA and HNA antibodies. Patients developing TRALI received more blood products containing HLA I, HLA II, and HNA antibodies compared with transfused controls $(\mathrm{P}=.005$; supplemental Table 1, available on the Blood Web site; see the Supplemental Materials link at the top of the online article). Of the 16 TRALI patients, $10(63 \%)$ had received a product containing antibodies. Further differentiation showed significant more HLA I and HLA II antibodies in the TRALI group $(\mathrm{P}=.01$ and 0.02 , respectively). In both the TRALI and transfused control cases, $80 \%$ of the HLA/HNA antibodypositive products originated from female donors. Of the RBCs, $\mathrm{n}=8(15 \%)$ were antibody-positive units and $\mathrm{n}=18(34 \%)$ were obtained from a female donor. Of the PLTs, $\mathrm{n}=7(37 \%)$ were antibody-positive units and $\mathrm{n}=13(68 \%)$ were obtained from a female donor. Of the FFP units, $\mathrm{n}=3(7 \%)$ were antibodypositive units and $n=2(5 \%)$ were obtained from a female donor. In line with previous reports, we show an association between the presence of antibodies in the products and sex of the donor. ${ }^{41}$ Of interest, excluding female donors for production of FFP as part of the National Blood Bank policy did not result in a decrease of TRALI incidence (2.4\% before vs $2.3 \%$ after exclusion, not significant). However, only $16 \%$ of the HLA/HNA antibody-positive units were FFP products. The remaining $84 \%$ were PLTs (40\%) and RBC products (44\%). These data suggest that in cardiac surgery patients, FFP products only play a minor role in the onset of immune-mediated TRALI. This study was not powered to investigate the effect of male only plasma. Therefore, conclusions as to whether male only plasma results in a reduction of TRALI cannot be determined from our results.

Univariate regression analysis showed that the total amount of plasma and the amount of RBC units, FFP units, and PLT units are all independent risk factors for developing TRALI compared with transfused controls (Table 4). Concerning causative factors, the number of RBC units stored more than 14 days, the total amount of lysoPCs, and the presence of HLA I, HLA II, or the composite of any antibody 
Vlaar, A.P.J., Hofstra, J.J., Determann, R.M., Veelo, D.P., Paulus, F., Kulik, W., Korevaar, J., Mol, B.A. de, Koopman, M.M.W., Porcelijn, L., Binnekade, J.M., Vroom, M.B., Schultz, M.J., Juffermans, N.P. The incidenge risk factors, and outcome of transfusion-related acute lung injury in a cohort of cardiac surgery patients. prospective nested case-control study. Blood: 2011, 117(16), 4218-4225

(HLA/HNA) in the transfused products are all independent risk factors for onset of TRALI compared with transfused controls. When adjusted for volume of products transfused, the association between lysoPCs and TRALI disappeared.

\section{[TABLE 3]}

\section{[TABLE 4]}

When adjusted for patient factors, only the presence of antibodies (HLA/HNA) in the blood product remained as a risk factor for the onset of TRALI compared with transfused controls.

\section{Outcome}

Patients developing TRALI were longer ventilated and had a greater length of ICU and hospital stay compared with transfused controls and nontransfused controls $(\mathrm{P}<.05$ for all, respectively; Table 3$)$. Hospital mortality was higher in patients developing TRALI compared with transfused controls $(\mathrm{P}<.05)$.

\section{DISCUSSION}

In this prospective study, the incidence of TRALI is high in a population of elective cardiac surgery patients compared with the general hospital population. ${ }^{11,12,42}$ In this cohort, the presence of antibodies, but not the amount of lysoPCs, was a risk factor for the onset of TRALI.

Our study reports, for the first time, the incidence of TRALI in a cohort of cardiac surgery patients. The incidence is high compared with the general hospital population ${ }^{11,12,42}$ and comparable with other studies identifying TRALI in the critically ill. ${ }^{6,8,10}$ It has been suggested that the diagnosis of TRALI may be problematic in cardiac surgery patients based on confounding factors that may contribute to hypoxemia. ${ }^{43}$ However, applying the consensus definition, we show that TRALI is a significant problem in this patient population. Our findings that only a minority of the cases was reported to the blood bank support the general notion that TRALI is underdiagnosed and under-reported.

Patients developing TRALI were older, with a concomitant higher EUROscore and ASA score, which are indicative of operation risk. In addition, time on the cardiopulmonary bypass machine was longer compared with control patients. Extracorporeal circulation has been shown to result in neutrophil priming. ${ }^{24,25} \mathrm{We}$ hypothesize that priming of the neutrophils may increase with the time on the bypass, thereby increasing the severity of the "first event" and the susceptibility to a TRALI reaction. A threshold model has been proposed,${ }^{19}$ in which the presence of a strong "first event" may require only a weak second event before TRALI occurs. ${ }^{44-46}$ In accordance, in a mouse model of TRALI, the presence of an inflammatory reaction resulted in onset of TRALI after a lower dose of antibodies compared with healthy controls. ${ }^{47,48}$ Our data suggest that patients with an expected prolonged time on the cardiopulmonary bypass may benefit from HLA/HNA antibody-free blood products. Logistic and financial analysis should show whether this is feasible. In terms of preventing transfusion-associated adverse events, off-pump procedure may be a favorable alternative.

We were able to confirm the association between leukocyte antibodies in blood products and the onset of TRALI. When adjusted for patient risk factors, the presence of antibodies in the transfused products remained an important risk factor for the onset of TRALI, irrespective of the volume of blood transfused. In line with previous results, we show that the majority of HLA/HNA antibody-positive donors are female. The higher incidence of HLA/HNA antibodies in female donors may be explained by alloimmunization during pregnancies. ${ }^{41}$ Given the association of female donors with TRALI, the United Kingdom National Blood Service deferred women from plasma donation since 2003. Since then, reports show a decrease in TRALI cases reported. ${ }^{27}$ Two clinical studies have appeared, indicating that excluding female donor plasma may prove effective in reducing pulmonary complications after blood transfusion. ${ }^{28,49}$ Although the policy of excluding female donors for FFP products by the Dutch National Blood Bank did not result in a decrease in TRALI incidence in the present study, it should be noted that during the study period plasma of female donors was used for preparation of PLTs and RBC products. In accordance, the association with onset of TRALI was strongest for PLTs, which contain a high amount of plasma in the product. Of note, the Dutch National Blood Bank started after the study was finished, with the use of male only plasma for the preparation of PLT products. Furthermore, plasma volumes in RBCs units as small as 10 to $20 \mathrm{~mL}$ 
Vlaar, A.P.J., Hofstra, J.J., Determann, R.M., Veelo, D.P., Paulus, F., Kulik, W., Korevaar, J., Mol, B.A. de, Koopman, M.M.W., Porcelijn, L., Binnekade, J.M., Vroom, M.B., Schultz, M.J., Juffermans, N.P. The incidenqe risk factors, and outcome of transfusion-related acute lung injury in a cohort of cardiac surgery patients. prospective nested case-control study. Blood: 2011, 117(16), 4218-4225

containing donor-derived antibodies are sufficient to cause TRALI. ${ }^{50}$ Our results suggest that either exclusion of all female donor blood for preparation of all blood products or exclusion of those tested positive for the presence of antibodies may reduce TRALI incidence. A policy of screening and excluding donors based on a certain cut-off titer of HLA/HNA antibodies ${ }^{51}$ may not reduce TRALI incidence in patients with a priming condition, as experimental data suggest that the presence of a "first event" requires a lower titer of HLA/HNA antibodies for the onset of TRALI. ${ }^{47}$

Previous retrospective studies have shown conflicting results on the role of storage of RBCs on outcome in cardiac surgery. ${ }^{30,31}$ The mechanism by which stored blood causes lung injury may be through passive infusion of lysoPCs, which accumulate during storage of RBCs and PLTs. ${ }^{22,44}$ In this study, we show an association between the number of transfused RBC products stored for more than 14 days and the onset of TRALI. This association disappeared after adjusting for patient risk factors. In addition, the total amount of lysoPCs infused was associated with the onset of TRALI. However, this association disappeared when adjusted for volume of products transfused. Therefore, the amount of lysoPCs seems merely to reflect RBC volume. In line with this, we recently showed that aged blood products cause TRALI in rats both in the presence and absence of accumulation of bioactive lipids, ${ }^{45,46}$ suggesting that the link between lysoPCs and lung injury is not strong. Taken together, the present results do not indicate that a transfusion policy of fresh blood only is beneficial in reducing TRALI.

\section{CONCLUSION}

Our study shows that onset of TRALI is associated with longer ventilation and admission time. Generally, TRALI is stated to have a good prognosis ${ }^{52}$; however, recent studies underline that TRALI is associated with increased mortality. ${ }^{6,10}$ In our institution, overall mortality of cardiac surgery patients is $4 \%$, which compares unfavorably with the $13 \%$ mortality of patients acquiring TRALI.

In conclusion, the incidence of TRALI is high in cardiac surgery patients, contributing to adverse outcome. Risk factors include duration of cardiopulmonary bypass and transfusion of antibody-containing blood products. Results suggest that cardiac surgery patients may benefit from exclusion of HLA or HNA antibody-positive blood.

\section{REFERENCES}

1. Goldman M, Webert KE, Arnold DM, Freedman J, Hannon J, Blajchman MA. Proceedings of a

consensus conference: towards an understanding of TRALI. Transfus Med Rev. 2005;19(1):2-31.

2. Holness L, Knippen MA, Simmons L, Lachenbruch PA. Fatalities caused by TRALI.

Transfus Med Rev. 2004;18(3):184-188.

3. Kleinman $S$, Caulfield T, Chan $P$, et al. Toward an understanding of transfusion-related acute lung injury: statement of a consensus panel. Transfusion.

2004;44(12):1774-1789.

4. Stainsby $D$, Jones $H$, Asher $D$, et al. Serious hazards of transfusion: a decade of hemovigilance in the

UK. Transfus Med Rev. 2006;20(4):273-282.

5. Toy P, Popovsky MA, Abraham E, et al. Transfusionrelated acute lung injury: definition and review.

Crit Care Med. 2005;33(4):721-726.

6. Gajic O, Rana R, Winters JL, et al. Transfusionrelated acute lung injury in the critically ill: prospective nested case-control study. Am J Respir

Crit Care Med. 2007;176(9):886-891.

7. Popovsky MA, Abel MD, Moore SB. Transfusionrelated acute lung injury associated with passive transfer of antileukocyte antibodies. Am Rev

Respir Dis. 1983;128(1):185-189.

8. Rana R, Fernandez-Perez ER, Khan SA, et al.

Transfusion-related acute lung injury and pulmonary edema in critically ill patients: a retrospective study.

Transfusion. 2006;46(9):1478-1483.

9. Silliman CC, Boshkov LK, Mehdizadehkashi Z, et al. Transfusion-related acute lung injury: epidemiology and a prospective analysis of etiologic factors. Blood. 2003;101(2):454-462.

10. Vlaar AP, Binnekade JM, Prins D, et al. Risk factors and outcome of transfusion-related acute lung injury in the critically ill: a nested casecontrol study. Crit Care Med. 2010;38(3):771-778.

11. Wallis JP, Lubenko A, Wells AW, Chapman CE.

Single hospital experience of TRALI. Transfusion. 
Vlaar, A.P.J., Hofstra, J.J., Determann, R.M., Veelo, D.P., Paulus, F., Kulik, W., Korevaar, J., Mol, B.A. de, Koopman, M.M.W., Porcelijn, L., Binnekade, J.M., Vroom, M.B., Schultz, M.J., Juffermans, N.P. The incidenge risk factors, and outcome of transfusion-related acute lung injury in a cohort of cardiac surgery patients. a prospective nested case-control study. Blood: 2011, 117(16), 4218-4225

2003;43(8):1053-1059.

12. Wiersum-Osselton JC, Porcelijn L, van Stein D, Vlaar AP, Beckers EA, Schipperus MR. [Transfusionrelated acute lung injury (TRALI) in the Netherlands in 2002-2005]. Ned Tijdschr Geneeskd.

2008;152(32):1784-1788.

13. Williamson LM, Lowe S, Love EM, et al. Serious hazards of transfusion (SHOT) initiative: analysis of the first two annual reports. BMJ. 1999; 319(7201):16-19.

14. Benson AB, Austin GL, Berg M, et al. Transfusion- related acute lung injury in ICU patients admitted with gastrointestinal bleeding. Intensive

Care Med. 2010;36(10):1710-1717.

15. Kopko PM, Marshall CS, MacKenzie MR, Holland PV, Popovsky MA. Transfusion-related acute lung injury: report of a clinical look-back investigation. JAMA. 2002;287(15):1968-1971.

16. Popovsky MA, Chaplin HC Jr, Moore SB. Transfusion- related acute lung injury: a neglected, serious complication of hemotherapy. Transfusion.

1992;32(6):589-592.

17. Popovsky MA. Transfusion and lung injury. Transfus

Clin Biol. 2001;8(3):272-277.

18. Wallis JP. Transfusion-related acute lung injury (TRALI): under-diagnosed and under-reported.

Br J Anaesth. 2003;90(5):573-576.

19. Bux J, Sachs UJ. The pathogenesis of transfusion- related acute lung injury (TRALI). Br J

Haematol. 2007;136(6):788-799.

20. Vlaar AP, Porcelijn L, Van Rooijen Schreurs I, Lardy NM, Kersten MJ, Juffermans NP. The divergent clinical presentations of transfusion-related acute lung injury illustrated by two case reports.

Med Sci Monit. 2010;16(10):CS129-CS134.

21. Silliman CC, Paterson AJ, Dickey WO, et al. The association of biologically active lipids with the development of transfusion-related acute lung injury: a retrospective study. Transfusion. 1997; 37(7):719726.

22. Silliman CC, Voelkel NF, Allard JD, et al. Plasma and lipids from stored packed red blood cells cause acute lung injury in an animal model. $\mathrm{J}$ Clin

Invest. 1998;101(7):1458-1467.

23. Silliman CC, Bjornsen AJ, Wyman TH, et al.

Plasma and lipids from stored platelets cause acute lung injury in an animal model. Transfusion.

2003;43(5):633-640.

24. Cameron D. Initiation of white cell activation during cardiopulmonary bypass: cytokines and receptors. J Cardiovasc Pharmacol. 1996; 27(suppl 1):S1-S5.

25. Gillinov AM, Bator JM, Zehr KJ, et al. Neutrophil adhesion molecule expression during cardiopulmonary bypass with bubble and membrane oxygenators.

Ann Thorac Surg. 1993;56(4):847-853.

26. Stover EP, Siegel LC, Parks R, et al. Variability in transfusion practice for coronary artery bypass surgery persists despite national consensus guidelines: a 24-institution study. Institutions of the Multicenter Study of Perioperative Ischemia Research Group. Anesthesiology. 1998;88(2): 327-333.

27. SHOT Annual report 2008. www.shotuk.org. Accessed October 15, 2010.

28. Vlaar AP, Binnekade JM, Schultz MJ, Juffermans NP, Koopman MM. Preventing TRALI: ladies first, what follows? Crit Care Med. 2008;36(12):3283- 3284.

29. Eder AF, Herron RM Jr, Strupp A, et al. Effective reduction of transfusion-related acute lung injury risk with male-predominant plasma strategy in the American Red Cross (2006-2008). Transfusion.

2010;50(8):1732-1742.

30. Koch CG, Li L, Sessler DI, et al. Duration of redcell storage and complications after cardiac surgery.

N Engl J Med. 2008;358(12):1229-1239.

31. van de Watering L, Lorinser J, Versteegh M, Westendord R, Brand A. Effects of storage time of red blood cell transfusions on the prognosis of coronary artery bypass graft patients. Transfusion.

2006;46(10):1712-1718.

32. van Straten AH, Soliman Hamad MA, Zundert AA, et al. Effect of duration of red blood cell storage on early and late mortality after coronary artery bypass grafting. J Thorac Cardiovasc Surg. 2010; 141(1):231-237.

33. Yap CH, Lau L, Krishnaswamy M, Gaskell M, Yii M. Age of transfused red cells and early outcomes after cardiac surgery. Ann Thorac Surg.

2008;86(2):554-559.

34. Patel R, Terasaki PI. Significance of the positive crossmatch test in kidney transplantation. N Engl J Med. 1969;280(14):735-739. 
Vlaar, A.P.J., Hofstra, J.J., Determann, R.M., Veelo, D.P., Paulus, F., Kulik, W., Korevaar, J., Mol, B.A. de, Koopman, M.M.W., Porcelijn, L., Binnekade, J.M., Vroom, M.B., Schultz, M.J., Juffermans, N.P. The incidenqe risk factors, and outcome of transfusion-related acute lung injury in a cohort of cardiac surgery patients: a prospective nested case-control study. Blood: 2011, 117(16), 4218-4225

35. De'cary F. VAEC: a look at HLA antisera in the indirect immunofluorescence technique (IIFT). In Kissmeyer-Nielsen F, ed. Histocompatibility testing.

1975:380-390.

36. Jiang AF, Lalezari P. A micro-technique for detection of leukocyte agglutinins. J Immunol Methods. 1975;7(1):103-108.

37. Verheugt FW, von dem Borne AE, Decary F, Engelfriet CP. The detection of granulocyte alloantibodies with an indirect immunofluorescence test. Br J Haematol. 1977;36(4):533-544.

38. Bux J, Kober B, Kiefel V, Mueller-Eckhardt C.

Analysis of granulocyte-reactive antibodies using an immunoassay based upon monoclonalantibodyspecific immobilization of granulocyte antigens. Transfus Med. 1993;3(2):157-162.

39. Middelburg RA, Porcelijn L, Lardy N, Briet E, Vrielink H. Prevalence of leucocyte antibodies in the Dutch donor population. Vox Sang. 2010 Oct 15 [Epub ahead of print].

40. Popovsky MA, Moore SB. Diagnostic and pathogenetic considerations in transfusion-related acute lung injury. Transfusion. 1985;25(6):573- 577.

41. Densmore TL. Prevalence of HLA sensitization in female apheresis donors. Transfusion. 1999; 39(1):103-106.

42. Clarke G. Severe respiratory reactions to random donor platelets: an incidence and nested casecontrol study [Abstract]. Blood. 1994;84(suppl 1): 465a.

43. Koch C, Li L, Figueroa P, Mihaljevic T, Svensson L, Blackstone EH. Transfusion and pulmonary morbidity after cardiac surgery. Ann Thorac Surg.

2009;88(5):1410-1418.

44. Kelher MR, Masuno T, Moore EE, et al. Plasma from stored packed red blood cells and MHC class I antibodies causes acute lung injury in a 2-event in vivo rat model. Blood. 2009;113(9): 2079-2087.

45. Vlaar AP, Hofstra JJ, Levi M, et al. Supernatant of aged erythrocytes causes lung inflammation and coagulopathy in a "two-hit" in vivo syngeneic transfusion model. Anesthesiology. 2010;113(1): 92-103.

46. Vlaar AP, Hofstra JJ, Kulik W, et al. Supernatant of stored platelets causes lung inflammation and coagulopathy in a novel in vivo transfusion model. Blood. 2010;116(8):1360-1368.

47. Looney MR, Nguyen JX, Hu Y, Van Ziffle JA, Lowell CA, Matthay MA. Platelet depletion and aspirin treatment protect mice in a two-event model of transfusion-related acute lung injury.

J Clin Invest. 2009;119(11):3450-3461.

48. Vlaar AP, Wolthuis EK, Hofstra JJ, et al. Mechanical ventilation aggravates transfusion-related acute lung injury induced by MHC-I class antibodies.

Intensive Care Med. 2010;36:879-887.

49. Wright SE, Snowden CP, Athey SC, et al. Acute lung injury after ruptured abdominal aortic aneurysm repair: the effect of excluding donations from females from the production of fresh frozen plasma. Crit Care Med. 2008;36(6):1796-1802.

50. Win N, Chapman CE, Bowles KM, et al. How much residual plasma may cause TRALI? Transfus Med. 2008;18(5):276-280.

51. Makar RS, Saidman SL, Stowell CP, Lee H, Powers A. Analysis of cutoffs for screening sensitized blood donors for HLA alloantibodies using a cytometric microbead assay. Transfusion. 2011; 51(1):166174.

52. Moore SB. Transfusion-related acute lung injury (TRALI): clinical presentation, treatment, and prognosis. Crit Care Med. 2006;34(suppl 5): S114-S117. 
Vlaar, A.P.J., Hofstra, J.J., Determann, R.M., Veelo, D.P., Paulus, F., Kulik, W., Korevaar, J., Mol, B.A. de, Koopman, M.M.W., Porcelijn, L., Binnekade, J.M., Vroom, M.B., Schultz, M.J., Juffermans, N.P. The incidenge risk factors, and outcome of transfusion-related acute lung injury in a cohort of cardiac surgery patients. 2 . prospective nested case-control study. Blood: 2011, 117(16), 4218-4225

Tables and figure

Figure 1

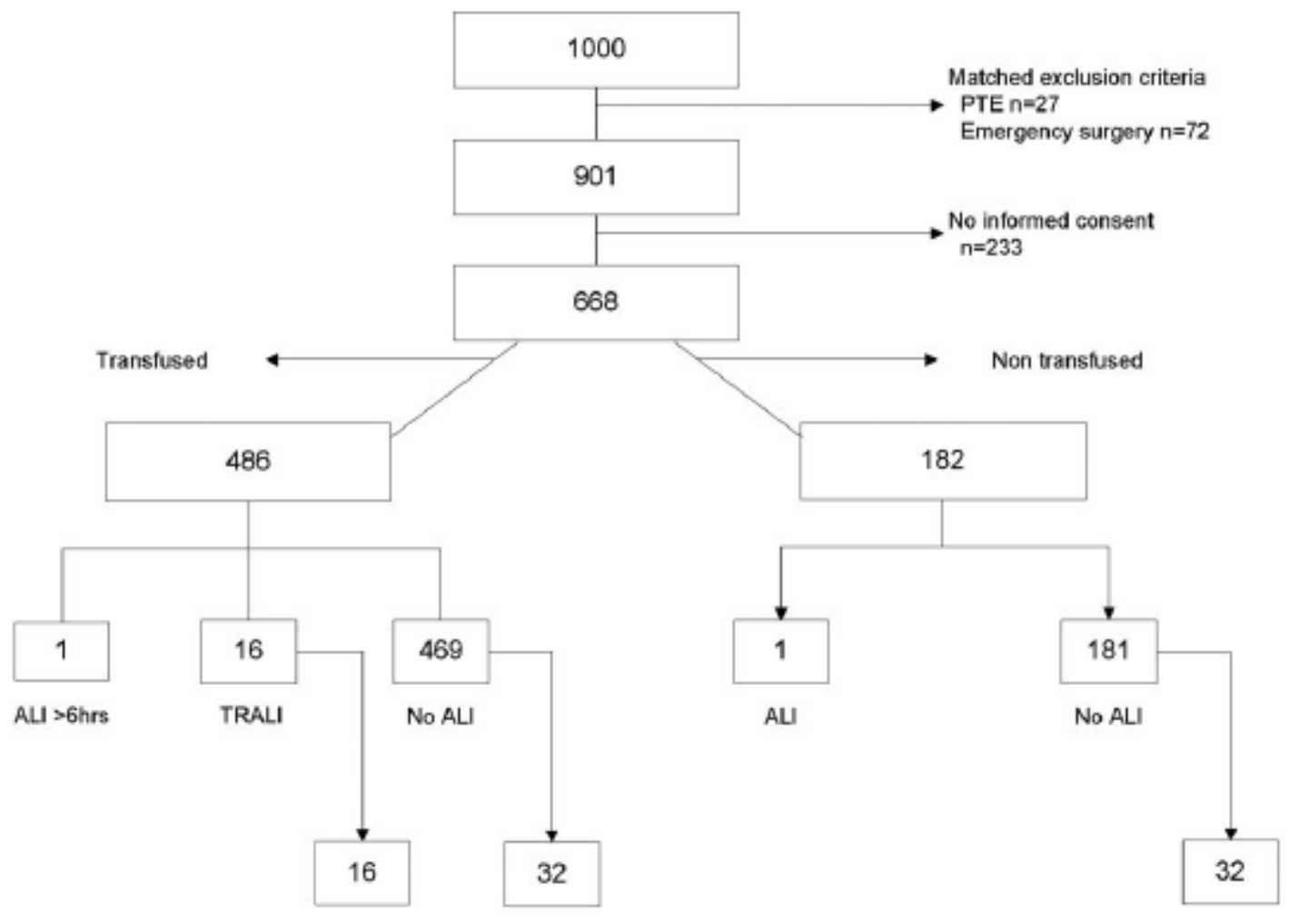

Table 1

Table 1. Transfusion characteristics of patients developing TRALI compared with transfused controls

\begin{tabular}{|c|c|c|c|}
\hline & TRAU $(n=16)$ & No ALI $(n=32)$ & $P$ \\
\hline Armount of tranefusions & $6(3-10)$ & $2(1-4)$ & $.04^{*}$ \\
\hline Modian FECa, urits, (ICR) & $3(2-5)$ & $2(1-2)$ &. $\mathscr{c}^{*}$ \\
\hline Modian FFP, unita, (ICR) & $2(0-4)$ & $0(0-2)$ &.$\infty$ \\
\hline Modim PLTa, urits, (1CR) & $1(0-2)$ & $0(0-1)$ &.$\infty 0^{\circ}$ \\
\hline \multicolumn{4}{|l|}{ RBCe } \\
\hline Sbrage time $>14 \mathrm{~d}$ units & $2(0-5)$ & $1(0-2)$ &.$\infty$ \\
\hline Modian storoge time, d (ICF) & $10(10-21)$ & $15(10-18)$ & .3 \\
\hline \multicolumn{4}{|l|}{ PLT2 } \\
\hline Slorage time $>5 \mathrm{~d}$ units & $0(0-1)$ & $0(0-1)$ & .0 \\
\hline Median aboroge time, $d\left(C_{C}\right)$ & $5(3-6)$ & $5(2-8)$ & .5 \\
\hline \multicolumn{4}{|l|}{ Plasma } \\
\hline Total plasma tranefused, $\mathrm{mL}$ & $1025(0-1737)$ & $680(0-\infty \infty 0)$ & $.01^{\circ}$ \\
\hline \multicolumn{4}{|c|}{ Amount of hysoPC transfused, modian (IOR) } \\
\hline LyscPC 16:0 $\mu \mathrm{mnd}$ & $30(2.1-60.8)$ & $1.6(1.1-28)$ & $.00 \Omega^{\circ}$ \\
\hline LysoPC $18: 0 \mu$ und & $12(1-23.4)$ & $0.8(0.5-10.8)$ & $.00 e^{\circ}$ \\
\hline LysoPC 18: 1 und & $6.1(0.7-12)$ & $0.5(0.3-5.7)$ & $.000^{\circ}$ \\
\hline LysoPAF 16:0 umd & $0.8(0.1-1.1)$ & $0.1(0.05-0.4)$ & $.000^{\circ}$ \\
\hline LysoPAF $16: 0 \mu \mathrm{mol}$ & $0.7(0.1-1.4)$ & $0.1(0.05-0.7)$ & $.000^{\circ}$ \\
\hline LyecPC 18: 1:PAF 16.0 urmsl & $0.3(0.04-0.5)$ & $0.03(0.02-0.2)$ & $.004^{*}$ \\
\hline \multicolumn{4}{|c|}{ Concentration of hyso PC per product, median (IOR) } \\
\hline LysoPC 16:0 $\mu \mathrm{mol}$ & $17(6.7-32.6)$ & $8.5(6.5-24.8)$ & .5 \\
\hline LyecPC $18: 0 \mu \mathrm{mnd}$ & $8.1(3.0-14.0)$ & $3.8(3.3-11.8)$ & .6 \\
\hline LysopC $18: 1$ und & $4.3(2.0-7.6)$ & $2.5(2.0-5.8)$ & .6 \\
\hline LysoPAF 16:0 umd & $0.4(0.3-0.8)$ & $0.4(0.3-0.5)$ & .5 \\
\hline LysoPAF $18: 0$ und & $0.8(0.3-1.1)$ & $0.4(0.4-0.8)$ & .6 \\
\hline LysoPC 18: 1,PAF $16 \times 0$ urmol & $0.2(0.1-0.4)$ & $0.2(0.2-0.3)$ & .7 \\
\hline \multicolumn{4}{|l|}{ Antibodies, $n(96)$} \\
\hline Any antibodyrpeetive, units & $10(63)$ & $4(13)$ & $.000^{\circ}$ \\
\hline Any HLA I-poeitive, urits & $6(39)$ & $1(3)$ & $.01^{*}$ \\
\hline Any HLA Il-positive, urits & $7(44)$ & $2(6)$ &. $\mathscr{C}^{*}$ \\
\hline Any GIFT-positivo, units & $3(10)$ & $1(3)$ & .2 \\
\hline
\end{tabular}

Data are mean (SO), modian (ICR), or $\mathrm{n}(\mathrm{s})$.

PLTs indizates platelet conceritrates; Plaems, high-volume phema produsts (FFP and PLTo); and GFT, Granulocyte ImmunoFlusrescense Teet.

"Sigrificant valus.

Table 2 
Vlaar, A.P.J., Hofstra, J.J., Determann, R.M., Veelo, D.P., Paulus, F., Kulik, W., Korevaar, J., Mol, B.A. de, Koopman, M.M.W., Porcelijn, L., Binnekade, J.M., Vroom, M.B., Schultz, M.J., Juffermans, N.P. The incidenqe risk factors, and outcome of transfusion-related acute lung injury in a cohort of cardiac surgery patients. 2 prospective nested case-control study. Blood: 2011, 117(16), 4218-4225

Table 2. Multivariate analysis of risk factors for the onset of TRALI in cardiac surgery patients

\begin{tabular}{|c|c|c|c|c|}
\hline & Unadjuated OR $(968 \mathrm{Cl})$ & $p$ & Adjusted $\mathrm{OR}^{*}(95 \% \mathrm{Cl})$ & $p$ \\
\hline ASA & $2.4(0.51-11.1)$ & .27 & Na & \\
\hline Age of the patient & $1.1(1.02-1.28)$ & $.03 \dagger$ & Na & \\
\hline Purmp time, min & $1.0(1.00-1.03)$ & $.02 \dagger$ & $\mathrm{Na}$ & \\
\hline Amsunt of traneluzions & $1.2(1.07-1.44)$ & $.010 \dagger$ & $1.1(0.90-1.37)$ & 3 \\
\hline RBCo, urits & $1.5(1.01-2.08)$ & $.045 t$ & $1.2(0.73-1.09)$ & $s$ \\
\hline FFP, urits & $1.4(1.04-1.88)$ & cost & $1.2(0.83-1.80)$ & 4 \\
\hline PLTs, urits & $3.0(1.16-7.68)$ & $.023 \dagger$ & $1.7(0.52-5.50)$ & 4 \\
\hline \multicolumn{5}{|l|}{ RBCe } \\
\hline Sbrage time $>14 \mathrm{~d}$, units & $1.8(1.04-2.37)$ & $.03 t$ & $1.4(0.8 \theta-2.21)$ & .16 \\
\hline Sbrage time,d & $1.0(0.05-1.21)$ & .20 & $1.1(0.03-1.21)$ & 41 \\
\hline \multicolumn{5}{|l|}{ PLT/2 } \\
\hline Sbrage time $>5 \mathrm{~d}$, units & $2.4(0.50-10.5)$ & .24 & $2.2(0.36-12.9)$ & .40 \\
\hline Sbrage time, d & $1.2(0.50-2.28)$ & .87 & $2.4(0.68-8.12)$ & .18 \\
\hline \multicolumn{5}{|l|}{ Plasma } \\
\hline Total plasma tranefused, mL & $1.2(1.03-1.44)$ & $.02 \dagger$ & $1.0(0.00-1.00)$ & .2 \\
\hline \multicolumn{5}{|l|}{ Antibodies } \\
\hline Any antibodypostive, units & $8.8(1.9-44)$ & $.008 \dagger$ & $14.2(1.53-132)$ & $.02 \dagger$ \\
\hline Any HLA I-positive, urits & $12(1.23-117)$ & $.03 \dagger$ & $7.0(0.72-87)$ &.$\infty 0$ \\
\hline Any HLA II-positive, urits & $7.5(1.23-46)$ & $.03 t$ & $5.5(0.71-41)$ & .11 \\
\hline Any GIFT-poetivo, units & $4.4(0.4-47)$ & 3 & $5.8(0.37-\infty 0)$ & 21 \\
\hline \multicolumn{5}{|c|}{ Total amount of Lyeo PC transfused } \\
\hline LyecPC 16:0 und & $1.0(1.01-1.07)$ & 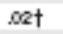 & $1.0(0.00-1.07)$ & 3 \\
\hline LysoPC $18.0 \mu \mathrm{mol}$ & $1.1(1.01-1.17)$ &.$\alpha 2 t$ & $1.1(0.96-1.16)$ & 3 \\
\hline LysoPC 1E: 1 und & $1.2(1.04-1.42)$ & $\alpha 2 \dagger$ & $1.1(0.91-1.40)$ & 3 \\
\hline LysoP AF 16:0 $\mu \mathrm{mol}$ & $8.4(1.40-47.2)$ &.$\alpha 2 \dagger$ & $3.2(0.37-43)$ & 3 \\
\hline LyeoP AF 18:0 umd & $4.3(1.29-14.4)$ & $.02 \dagger$ & $2.5(0.50-14)$ & 3 \\
\hline LyecPC 18: 1/PAF 16:0 $\mu \mathrm{mol}$ & $23.8(0.00-5070)$ & ast & $16.4(0.12-2275)$ & 3 \\
\hline \multicolumn{5}{|c|}{ Concentration of lyso PC/product } \\
\hline LysoPC 16:0 umol & $1.0(0.00-1.10)$ & .1 & $1.0(0.06-1.07)$ & 8 \\
\hline LysoPC $18.0 \mu \mathrm{mol}$ & $1.1(0.091 .21)$ & .1 & $1.0(0.00-1.15)$ & 8 \\
\hline LysoPC 1e:1 $\mu \mathrm{mol}$ & $1.2(0.95-1.56)$ & .1 & $1.1(0.80-1.40)$ & .7 \\
\hline LysoP AF 16:0 $\mu \mathrm{mol}$ & $6.1(0.35-104)$ & 2 & $0.7(0.02-22)$ & 8 \\
\hline LysoPAF $18: 0$ und & $3.3(0.52-22.3)$ & 2 & $1.0(0.10-0.4)$ & 1.0 \\
\hline LysopC 18: 1:PAF $16.20 \mathrm{~mm}$ & $25.0(0.1-6406)$ & 3 & $1.7(0.00-1073)$ & .2 \\
\hline
\end{tabular}

Data are mean (SD) or medan (IOR).

NAindcates not opplicable; and GIFT, Granulocylo hmunoFluonesconce Tost. "Adjusted for age of the potierk and pump time during cardiopulmonary bypase. †Signiricant valus.

Table 3 
Vlaar, A.P.J., Hofstra, J.J., Determann, R.M., Veelo, D.P., Paulus, F., Kulik, W., Korevaar, J., Mol, B.A. de, Koopman, M.M.W., Porcelijn, L., Binnekade, J.M., Vroom, M.B., Schultz, M.J., Juffermans, N.P. The incidenqe risk factors, and outcome of transfusion-related acute lung injury in a cohort of cardiac surgery patients. 2 prospective nested case-control study. Blood: 2011, 117(16), 4218-4225

Table 3. Demographic and clinical characteristics of cardiac surgery patients developing TRALI and control patients

\begin{tabular}{|c|c|c|c|}
\hline & \multicolumn{2}{|c|}{ Transfused goups } & \multirow[b]{2}{*}{ Nontransfused group: no $\mathrm{ALI}(\mathrm{n}=32$ ) } \\
\hline & TRALI $(n=16)$ & No ALI $(n=32)$ & \\
\hline$A g e, y(S D)$ & $74(7.4)^{*}$ & $67(0.3) \dagger$ & $63(13) 53$ \\
\hline Malo sex, n (\%) & $12(75)$ & $20(63)$ & $28(89)$ \\
\hline EUAOscore, mean (SO) & $6.4(2.8)$ & $5.8(3.3)$ & $3.9(2,4) \xi 5$ \\
\hline ASA, moan (SO) & $3.3(0.5)$ & $3.1(0.5)$ & $2.7(0.8) \mid$ \\
\hline \multicolumn{4}{|l|}{ Modical hiatory } \\
\hline Alcohol abuse, $n(\%)$ & $1\langle 6\rangle$ & $2(6)$ & $0(0)$ \\
\hline Smoking $n(\%)$ & $2(13)$ & $\rho(28)$ & $\odot(29)$ \\
\hline Myocardial irfaretion, $n(x)$ & $2(13)$ & $11(34)$ & $10(31)$ \\
\hline Hyporternsion, $n(\%)$ & $8(50)$ & $24(75)$ & $17(53)$ \\
\hline Disbotes, $n(\%)$ & $4(25)$ & $12(38)$ & $3(9)$ \\
\hline Vascular dizeases, $n$ (\%) & $3(10)$ & $10\langle 31\rangle$ & $3(0)$ \\
\hline Malignanay, $n(\%)$ & $1(8)$ & $3(0)$ & $0(0)$ \\
\hline$C V A, n(*)$ & $3(10)$ & $1(3)$ & $2(8)$ \\
\hline Aubimmune, $n(s)$ & $1(6)$ & $2\langle 6\rangle$ & $\theta(29)^{\circ}$ \\
\hline \% prodictivo vital copacity, mean (SD) & $\infty(31)$ & $\infty 8(15)$ & $100(18)$ \\
\hline \% prodictivo FEV ${ }_{1}$, moan (SO) & $70(31)$ & $88\langle 17\rangle$ & $\infty 8(21)$ \\
\hline \multicolumn{4}{|l|}{ Loft wontrioular function } \\
\hline Poor & $1(6)$ & $5(16\rangle$ & $1(3)$ \\
\hline Moderate & $7(44)$ & $5(16)$ & $7(22)$ \\
\hline Good & $8(50)$ & $22(60)$ & $22(\theta 0)$ \\
\hline \multicolumn{4}{|l|}{ Preoperative } \\
\hline Moan homogobin, rmM, (SD) & $8.8\langle 1.0\rangle$ & $8.5(0.8\rangle$ & $0.2(0.8)$ \\
\hline Modian PLT courk, $\times 10^{\circ},($ IOR) & $213(178-249)$ & $240(200-200)$ & $231(197-260)$ \\
\hline Modian leukocjte count, $\times 10^{\circ}$, (IOR) & $7.8(5.6-9.9)$ & $7.8(6.6-9.8)$ & $7.0(8.2-8.7)$ \\
\hline Mean urea, mM, (SO) & $7.4(2.5)$ & $6.8(2.8\rangle$ & $6.4(1.5)$ \\
\hline Mean croatinine, mM, (SD) & $03(25)$ & $85(23)$ & $83(15)$ \\
\hline Moan INR, (SD) & $1.1(0.2\rangle$ & $1.1(0.3\rangle$ & $1.2(0.8)$ \\
\hline \multicolumn{4}{|l|}{ Type of eurgery } \\
\hline $\mathrm{CABG}, \mathrm{n}(\mathrm{m})$ & $6(38)$ & $15(47)$ & $10(\theta 0)$ \\
\hline Valve replacement, n (\%) & $\theta(56)$ & $16(50)$ & $\theta(29)$ \\
\hline Bontal, $n(\$)$ & $1(8)$ & $0\langle 0\rangle$ & $2(8)$ \\
\hline Other, n (\$) & $0\langle 0\rangle$ & $1(3)$ & $2(\theta)$ \\
\hline \multicolumn{4}{|l|}{ Perioperativo } \\
\hline Modian clamp time, min (ICA) & $101(86-148) 5$ & $75(62-100) \ddagger$ & $74(49-94) 8$ \\
\hline Modian pump time, min (IOA) & $170(126-108)^{\circ}$ & $117(00-147) \dagger$ & $110(79-131) \mid$ \\
\hline Mean total surgery time, min (IOR) & $360(273-416)^{\circ}$ & $240(300-450) \dagger$ & $238(200-268) \mid$ \\
\hline Dexamothasons, $n(\%)$ & $6(38)$ & $3(0)$ & $\rho(29)$ \\
\hline Opicid use, $n(x)$ & $16(100)$ & $32(100)$ & $32(100)$ \\
\hline
\end{tabular}

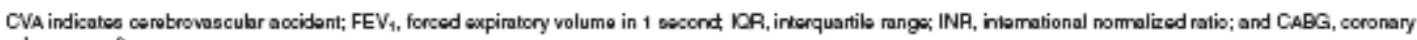
artery bypase graft.

$p<.05$, TRALI ve transiuead or nontransluesd cortrols.

$T P<.05$, Thal

†P

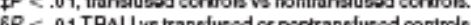

fP $<.001$, TRALI ve translueed or neritansfused controle.

Table 4

Table 4. Outcome of cardiac surgery patients developing TRALI and control groups

\begin{tabular}{|c|c|c|c|}
\hline & \multicolumn{2}{|c|}{ Tranefused groupe } & \multirow[b]{2}{*}{ Nontranafueed group: no ALI (n $=32$ ) } \\
\hline & $\operatorname{TRALI}(n=16)$ & No ALI (n = 32) & \\
\hline Modian ICU LOS, h, (ICA) & $180(70-172)^{*}$ & $45(29-66) \ddagger$ & $38(23-48)$ \\
\hline Modian hospital LOS, h, (ICR) & $381(216-524)^{*}$ & $216(169-384) \ddagger$ & $168(120-102)$ \\
\hline Modian vontibtion tims, h, (ICR) & $25(21-83)^{\circ}$ & $22(14-40) \neq$ & $14(10-18)$ \\
\hline Hospital mortality, $n$ (\$s) & $2(13) \dagger$ & $0(0)$ & $1(3)$ \\
\hline
\end{tabular}

LOS indizates length of olay.

$\bullet P<.001$, TRALI vo No ALI tranefused and No ALI nonitronsfused.

$t P<.05$, TRAL Ive No ALl transfused and No ALl nontransfused.

$\ddagger P<.05$, No ALI norktranefused va No ALI tranefused. 